\title{
Sonography of Benign Palpable Masses of the Elbow
}

\author{
Jee Young Lee, MD, Sung Moon Kim, MD, David P. Fessell, MD, Jon A. Jacobson, MD
}

Received December 29, 2010, from the Department of Radiology, Dankook University Hospital, Cheonan, Korea (J.Y.L.); and Department of Radiology, University of Michigan Medical Center, Ann Arbor, Michigan USA (S.M.K., D.P.F., J.A.J.). Revision requested January 17, 2011. Revised manuscript accepted for publication February 8, 2011.

Address correspondence to Sung Moon Kim, MD, Department of Radiology, University of Michigan Medical Center, 1500 E Medical Center Dr, TC-2910, Ann Arbor, MI 48109-0326 USA.

E-mail:sungmoon@med.umich.edu
The purpose of this pictorial essay is to show the sonographic appearances of benign masses found in and around the elbow, including fat-containing tumors, fibrous tumors, vascular lesions, selected skin lesions, and other miscellaneous lesions. Sonographic features, including the use of dynamic and color Doppler imaging, can be helpful in characterizing these masses and in narrowing the differential diagnosis.

Key Words_elbow; sonography; tumors

S onography has proven to be a useful modality for confirmation, initial assessment, evaluation, and therapeutic and diagnostic interventions of soft tissue masses. ${ }^{1}$ Soft tissue masses of the elbow can be secondary to tumors, infection, trauma, and inflammatory processes. ${ }^{2} \mathrm{We}$ will show the sonographic features of benign soft tissue masses of the elbow, including fat-containing tumors, fibrous tumors, vascular lesions, selected skin lesions, and other miscellaneous lesions. Sonography was performed with a high-frequency (5- to $17-\mathrm{MHz}$ ) linear transducer, and color Doppler images were also obtained. All lesions were surgically resected and pathologically proven.

\section{Fatty Tumors}

Lipomas are the most common soft tissue neoplasms, accounting for almost half of all soft tissue tumors. ${ }^{3}$ Lipomas can be suggested by sonography if elliptical or ovoid, avascular, compressible, and well defined within the subcutaneous fat. ${ }^{4}$ The echogenicity is variable from hypoechoic to hyperechoic, related to the number of internal interfaces between fat and other connective elements: the purer the fat, the more hypoechoic the sonographic appearance. ${ }^{4}$ A variant of a lipoma is an angiolipoma, characterized by a welldefined homogeneously echogenic mass (Figure 1$).^{5}$

\section{Fibrous Lesions}

\section{Desmoid-Type Fibromatosis}

Desmoid-type fibromatosis is a locally aggressive fibroblastic tumor arising from the connective tissue of muscle and its overlying aponeurosis or fascia. Typically, sonography shows a hypoechoic solid mass with well-defined or poorly defined borders and variable degrees of vascularity (Figure 2 ). ${ }^{6}$ 


\section{Solitary Fibrous Tumors}

Solitary fibrous tumors arising from the serosal or extraserosal sites are distinct types of benign spindle cell neoplasms that may present as painless palpable masses. ${ }^{7}$ In the soft tissues, a solitary fibrous tumor appears as a welldefined hypervascular mass with solid and cystic features in the intramuscular, perifascial, or subcutaneous layers. On sonography, a solitary fibrous tumor appears as a welldefined ovoid hypoechoic solid mass with internal vascular flow in the deep subcutaneous layer (Figure 3).

Figure 1. Angiolipoma in a 33-year-old man. A, Sagittal sonogram obtained over the lateral aspect of elbow showing a relatively hyperechoic solid ovoid mass (calipers) in comparison to surrounding tissue located in the deep subcutaneous layer, which was slightly compressible. B, Corresponding color Doppler image showing no notable internal flow.

A

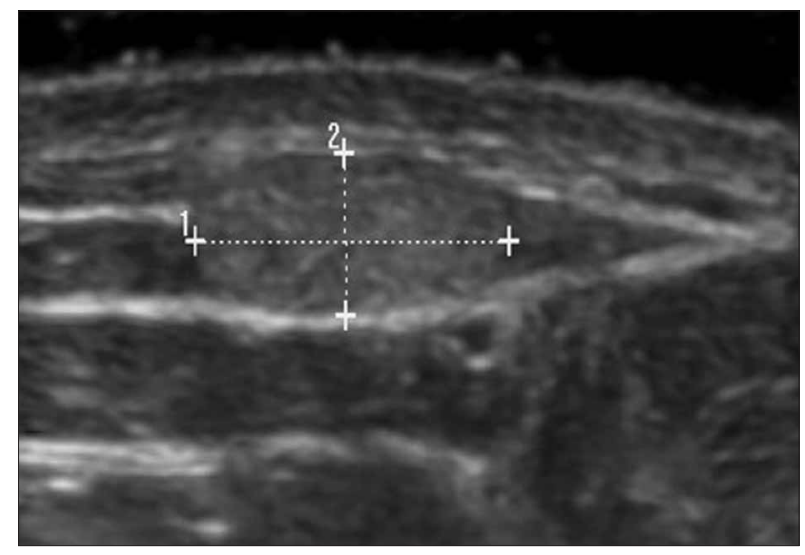

B

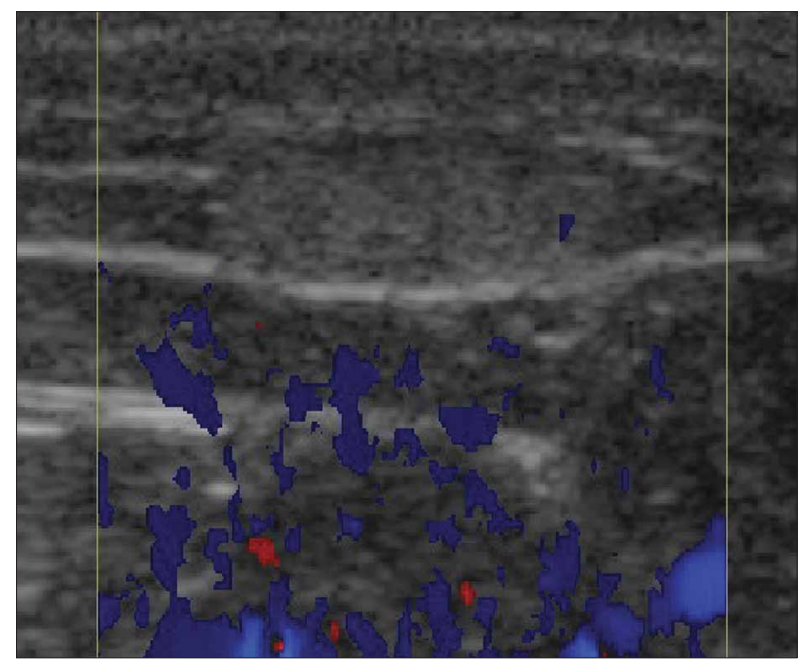

\section{Vascular Lesions}

\section{Vascular Malformations}

Vascular malformations are caused by anomalous morphogenesis of vessels and consist of abnormal channels lined by normal endothelium that have low cellular turnover. On sonography, they appear heterogeneous with possible anechoic fluid-filled cavities and variable degrees of Doppler signals depending on the channel type (arterial, venous, capillary, lymphatic, or combinations; Figure 4). Pulsatile arterial flow and arteriovenous shunting may be identified in high-flow malformations. Thrombosis and the absence of a Doppler signal may be seen in low-flow malformations. ${ }^{8}$

Figure 2. Desmoid-type fibromatosis in a 45-year-old woman. A, Transverse sonogram obtained over the posterior aspect of the elbow showing bulky mass with mixed echogenicity along the posteromedial aspect of the left elbow, abutting the medial epicondyle and partially enveloping and displacing the ulnar nerve (arrows). B, Sonogram showing a biopsy needle (arrows) within the mass.

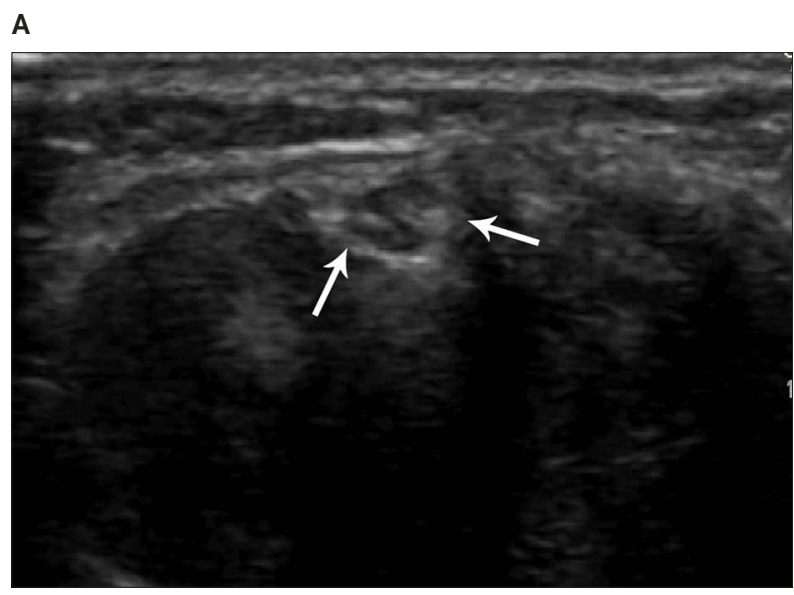

B

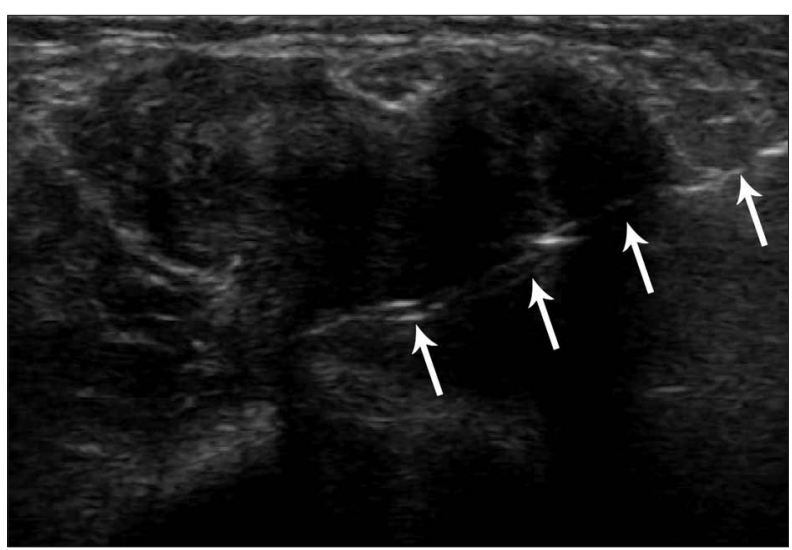




\section{Lymphangiomas}

Lymphangiomas are benign vascular tumors and are considered uncommon congenital lymphatic hamartomas, which can occur anywhere in the body. On sonography, they appear as unilocular or multilocular cystic lesions without vascular flow. ${ }^{9}$ They may insinuate around normal structures, as seen with other common vascular lesions (Figure 5).

\section{Papillary Endothelial Hyperplasia}

Papillary endothelial hyperplasia is a rare vascular tumor of the skin and soft tissues. The histopathologic diagnosis is made by the identification of distinctive papillary proliferations of endothelial cells arising within the vascular channel, occurring in the extremities. Gray scale and Doppler imaging with tourniquet application to distend

Figure 3. Solitary fibrous tumor in a 16-year-old boy. A, Transverse sonogram obtained over the lateral aspect of the elbow showing a hypoechoic solid ovoid mass (arrows) in the lateral aspect of the lateral head of the distal triceps brachii muscle (LHT), abutting the superficial fascia of the triceps. B, Corresponding color Doppler image showing flow within the mass.

\section{A}

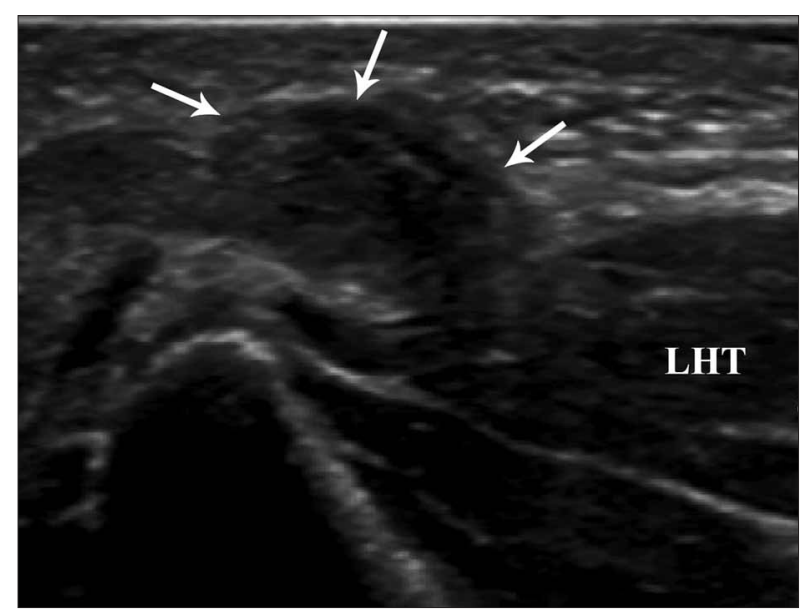

B

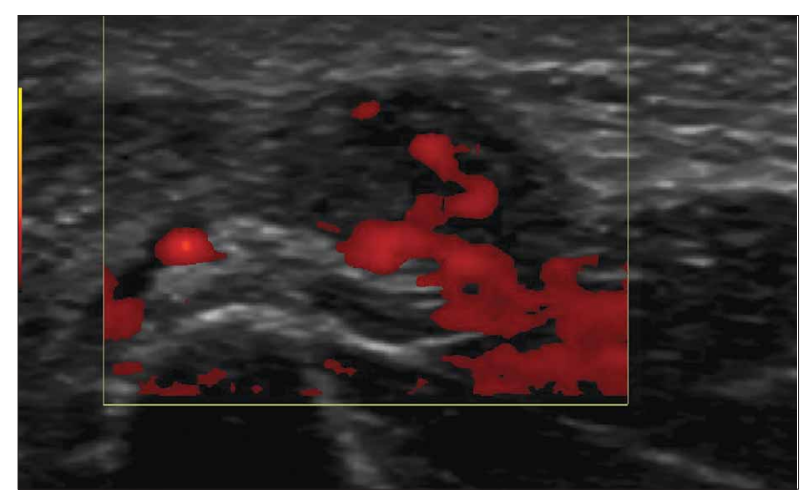

the vessels can confirm the intravascular location of the mass (Figure 6). ${ }^{10}$

\section{Lesions Associated with Skin Appendages}

\section{Epidermoid Cysts}

Epidermoid cysts result from proliferation of surface epidermal cells that have been displaced into the dermis, such as after a puncture wound. They are typically subepidermal and well encapsulated and can be filled with keratin and a varying amount of lipid-containing debris. Sonographically, they are usually well encapsulated and heterogeneous with through-transmission. ${ }^{11}$ Because of keratinor debris-induced internal echoes, they may look like solid masses; however, they can be compressed easily by the

Figure 4. Painful vascular malformation in a 17-year-old woman. A, Sagittal sonogram obtained over the forearm and elbow showing heterogeneous subcutaneous tissues with poorly defined regions of hypoechogenicity. B, Corresponding color Doppler image showing minimal flow (arrow).

A

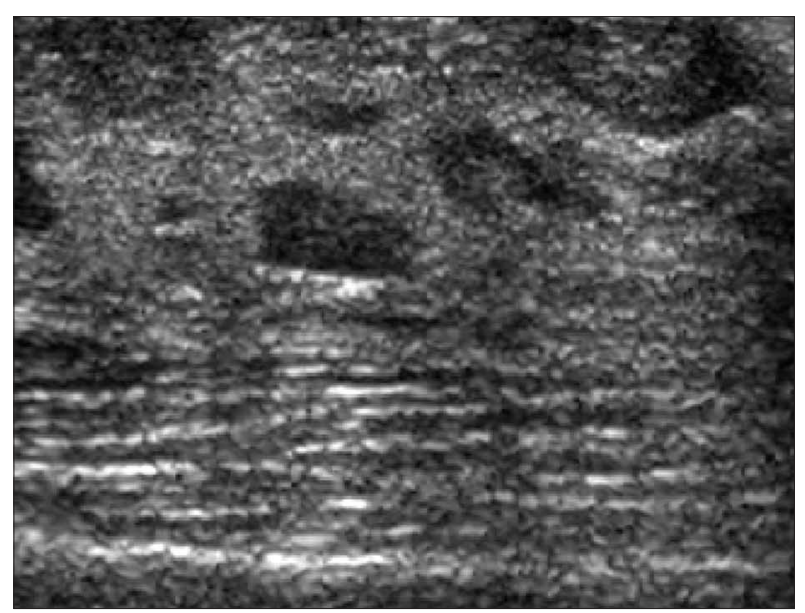

B

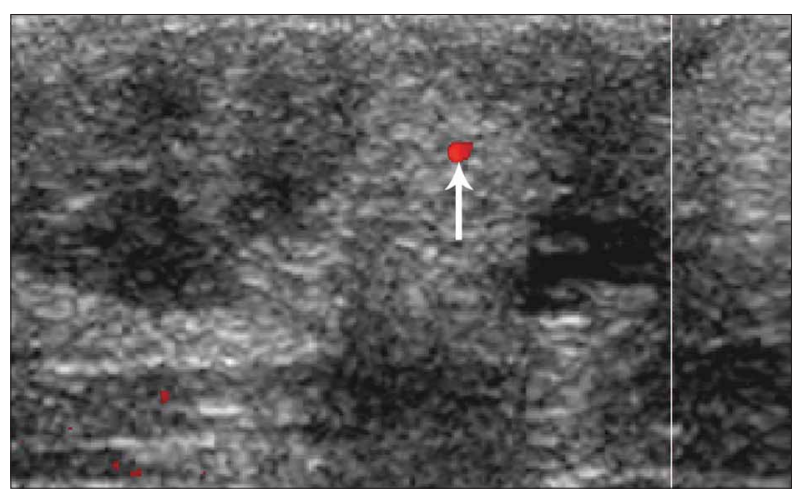


transducer, which can be a differential finding from a solid mass. If ruptured, they may have a lobulated shape with occasionally vascular flow in the periphery due to associated inflammation (Figure 7).

\section{Subcutaneous Granuloma Annulare}

Granuloma annulare is a common benign inflammatory skin lesion of unknown etiology. The subcutaneous form of granuloma annulare is of interest because of its deepseated location and its relatively high local recurrence rate (20\%) compared with other locations of granuloma annulare. On sonography, it appears as a poorly defined hypoechoic nodule with internal vascular flow located in the subcutaneous layer (Figure 8). ${ }^{12}$

Figure 5. Cavernous lymphangioma in a 5-year-old girl. A, Sagittal sonogram showing a well-defined inhomogeneous hypoechoic mass (between calipers) in the brachioradialis muscle with heterogeneous internal echoes and a bright echogenic rim, distinguishing the mass from adjacent muscle fibers. B, Transverse color Doppler image showing flow signals inside the mass and adjacent tissues. No feeding artery or draining vein is shown.

\section{A}

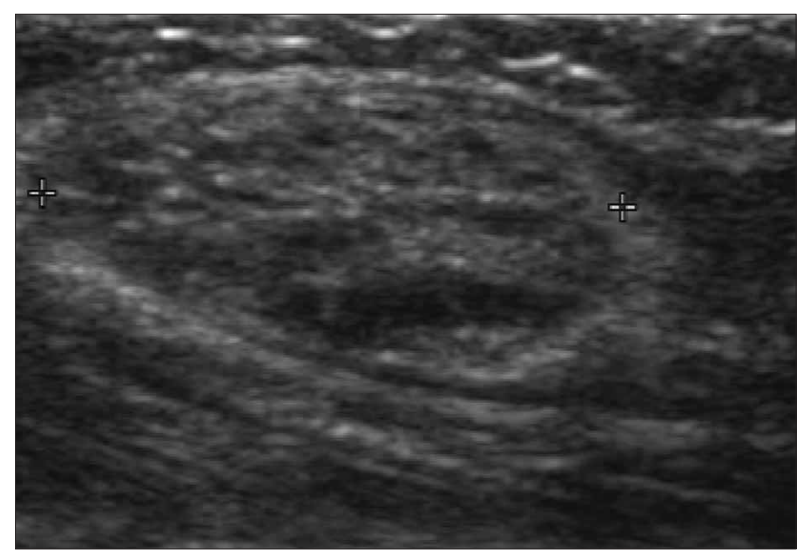

B

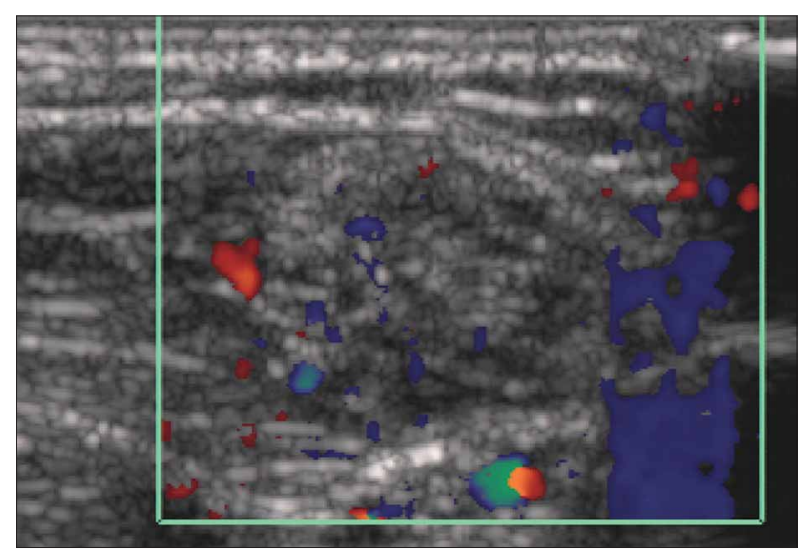

\section{Pilomatricomas}

Pilomatricomas are benign subcutaneous tumors of the head, neck, and extremities that arises from hair cortex cells. On sonography, they appear as hypoechoic masses in the subcutaneous tissues with internal echogenic structures secondary to calcifications. A peripheral hypoechoic rim and peripheral Doppler flow are often noted, as well as thinning of the overlying dermis (Figure 9). ${ }^{13}$

Figure 6. Papillary endothelial hyperplasia in a 41-year-old woman. A, Transverse sonogram obtained over the posterior aspect of the elbow showing a well-defined heterogeneous hypoechoic mass (arrows) within the medial aspect of the triceps brachii muscle. The mass was not compressible on dynamic imaging (not shown). B, Corresponding color Doppler image showing flow signals inside the mass and adjacent tissues, consistent with a solid mass.

A

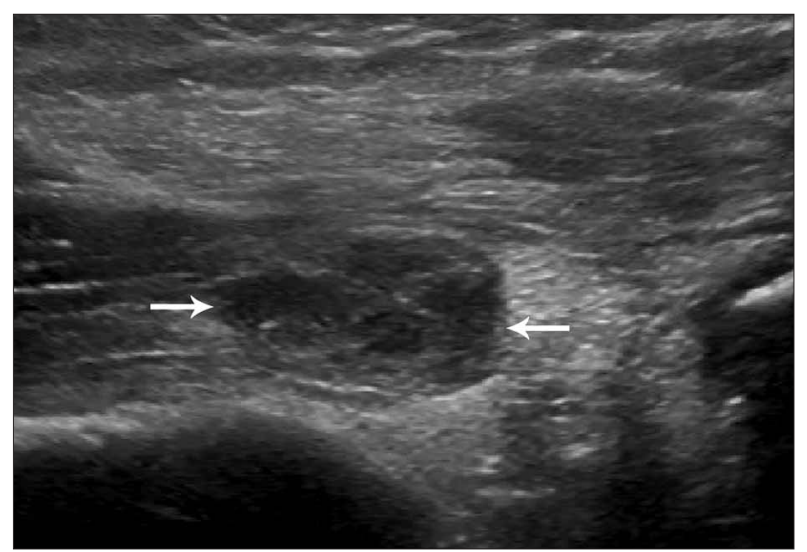

B

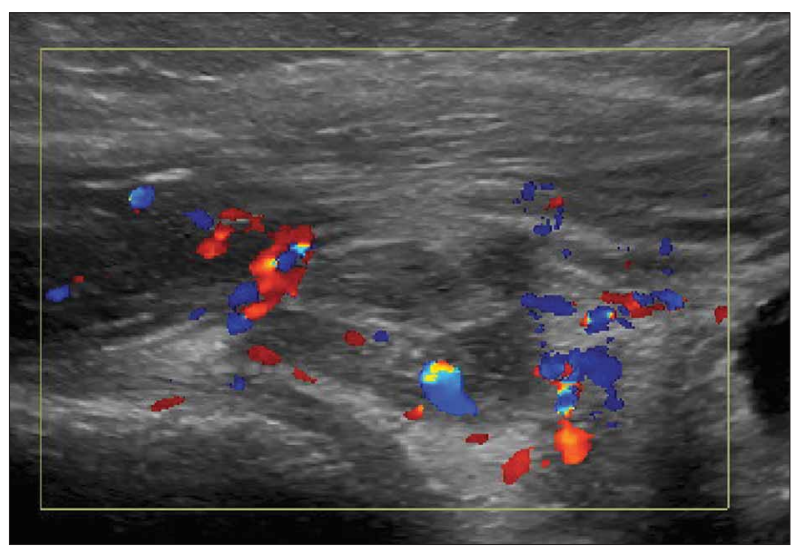


Figure 7. Ruptured epidermoid cyst in a 37-year-old man. A, Sagittal sonogram obtained over the dorsum of the proximal ulna showing a well-defined lobulated mass in the subcutaneous tissue with heterogeneous internal echoes and central clefts. The mass was mildly compressible (not shown). B, Sagittal sonogram with a extended field of view showing the relationship between the cyst and olecranon (OLEC). Color Doppler imaging did not show internal vascularity (not shown), Arrow and TRI indicate triceps tendon.

A

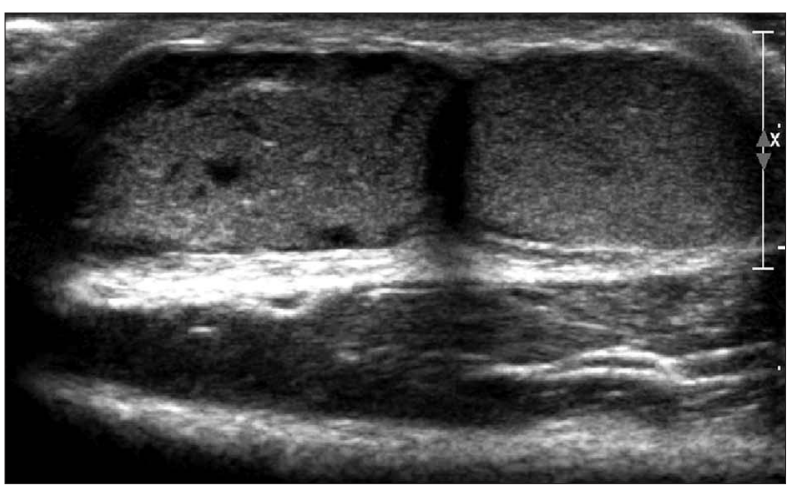

B

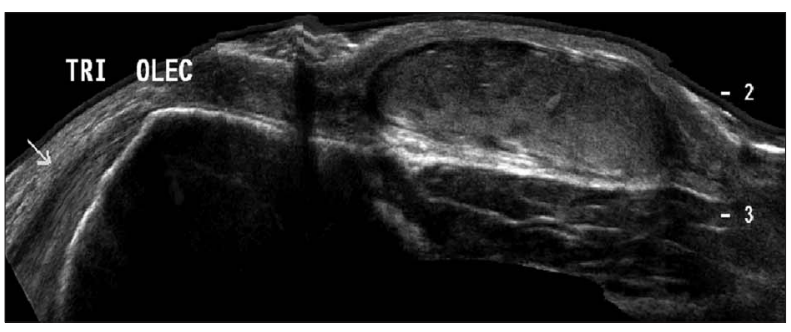

Figure 8. Subcutaneous granuloma annulare in a 6-year-old boy. A, Coronal sonogram obtained over the medial elbow showing a well-defined hypoechoic to anechoic mass (calipers). B, Corresponding color Doppler image showing internal duplex flow within the mass and surrounding tissues.

A

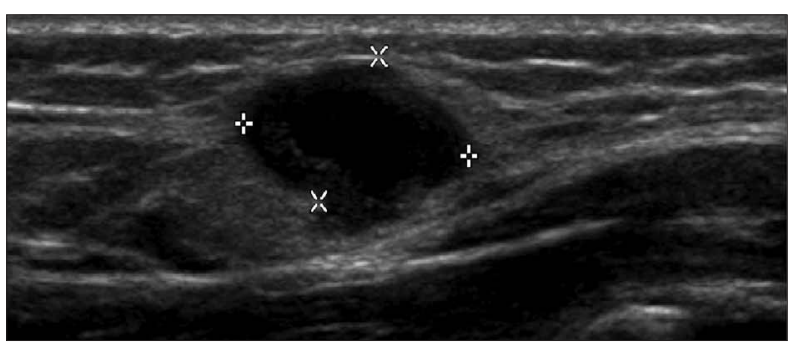

B

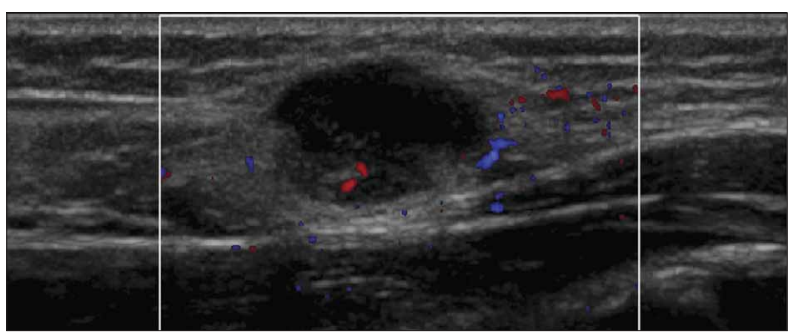

\section{Miscellaneous Lesions}

\section{Peripheral Nerve Sheath Tumors}

Classically benign peripheral nerve sheath tumors have been divided into schwannoma (or neurilemmoma) and neurofibroma. A benign peripheral nerve sheath tumor is usually hypoechoic with increased posterior through-transmission. The presence of peripheral nerve contiguity suggests the diagnosis of a peripheral nerve sheath tumor. Sonography cannot reliably distinguish a neurofibroma from a schwannoma (Figure 10)..$^{14}$

Figure 9. Pilomatricoma in a 47-year-old woman. A, Sagittal sonogram showing a well-defined noncompressible heterogeneous solid mass in the superficial subcutaneous tissue, just beneath the skin surface. A peripheral hypoechoic rim and variable internal echogenic foci (arrowheads) without posterior shadowing are shown. B, Corresponding color Doppler image showing flow in the peripheral portion of the mass.

A

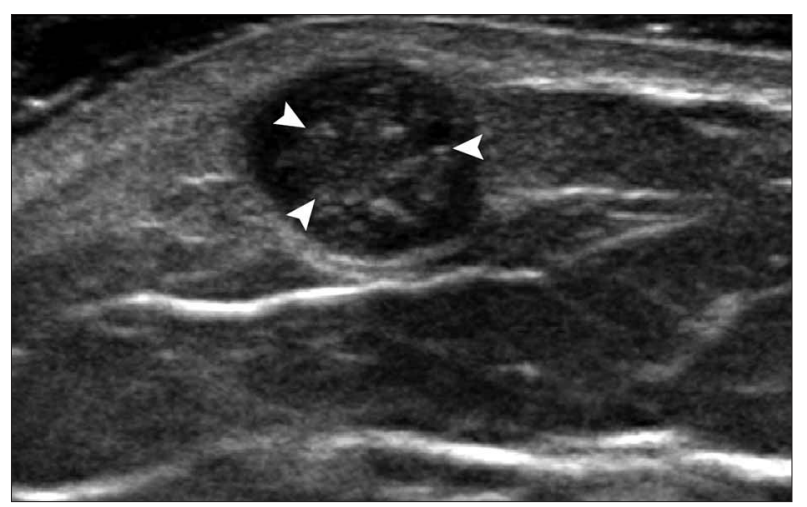

B

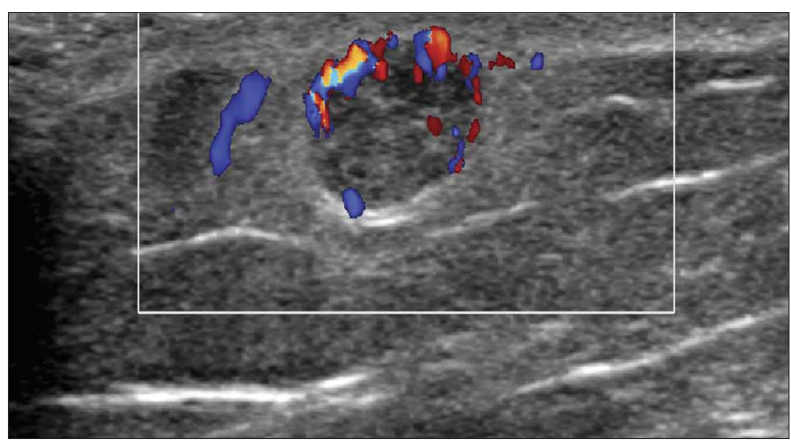




\section{Myxomas}

Myxomas are benign slow-growing soft tissue neoplasms that arise most commonly in the intramuscular compartment. Intrinsic features of a myxoma are similar to those of cysts because of high mucin and low cellular contents. On sonography, myxomas are well-defined ovoid hypoechoic masses with posterior through-transmission. A bright rim or bright cap sign around the mass has been reported secondary to muscle atrophy and increased fat deposition from the release of the mucoid material by the incompletely capsulated myxoma (Figure 11). ${ }^{15}$

Figure 10. Schwannoma arising from the fascicle of the ulnar nerve in an 82-year-old man. A, Sagittal sonogram showing a well-defined ovoid mass that has both cystic and solid components contiguous with the ulnar nerve. Entering and exiting nerve fascicles (arrowheads) are shown. B, Corresponding color Doppler image showing increased vascular flow (arrow) within the solid component.

\section{A}

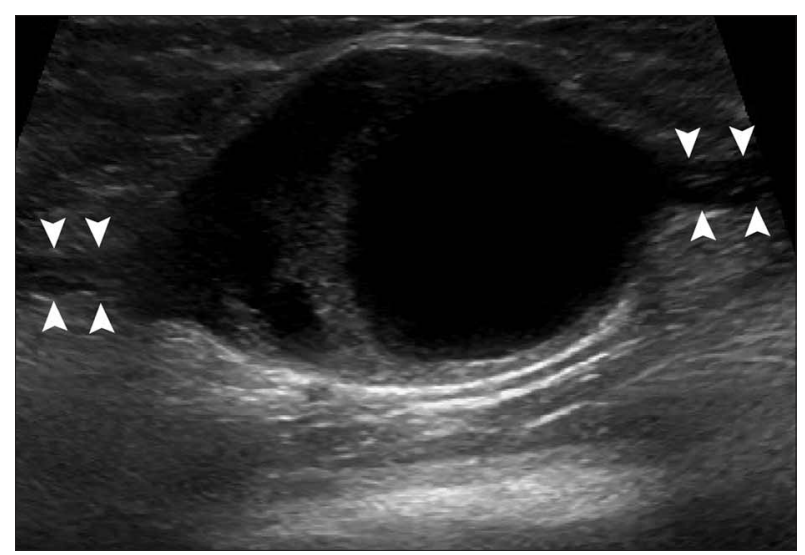

B

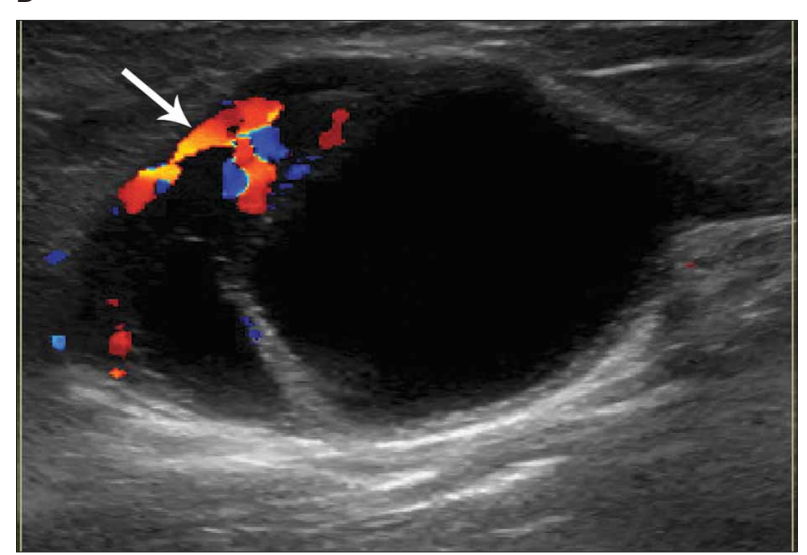

\section{Conclusions}

Sonography can be diagnostic for peripheral nerve sheath tumors and cysts. For myxomas, lipomas, and vascular lesions, sonography can be strongly suggestive, and if needed, magnetic resonance imaging can help in establishing a definitive diagnosis. In other solid tumors, sonography may not be definitive for diagnosis and may not exclude malignancy. In nondiagnostic cases, however, sonography can help narrow the differential diagnosis and aid surgical planning by showing the location and size of the mass and associated nerve, tendon, or vascular involvement. Sonography can also guide aspiration and biopsy.

Figure 11. Myxoma in a 35-year-old woman. A, Transverse sonogram showing a fairly well-defined but heterogeneous predominantly hypoechoic mass (arrowheads) within the brachioradialis muscle. A hyperechoic rim surrounds the mass, and intense posterior enhancement is shown. B, Corresponding color Doppler image showing minimal hyperemia with several intrinsic cystic or necrotic areas (asterisks). The superficial branch of the radial nerve was displaced by the mass (not shown).

A

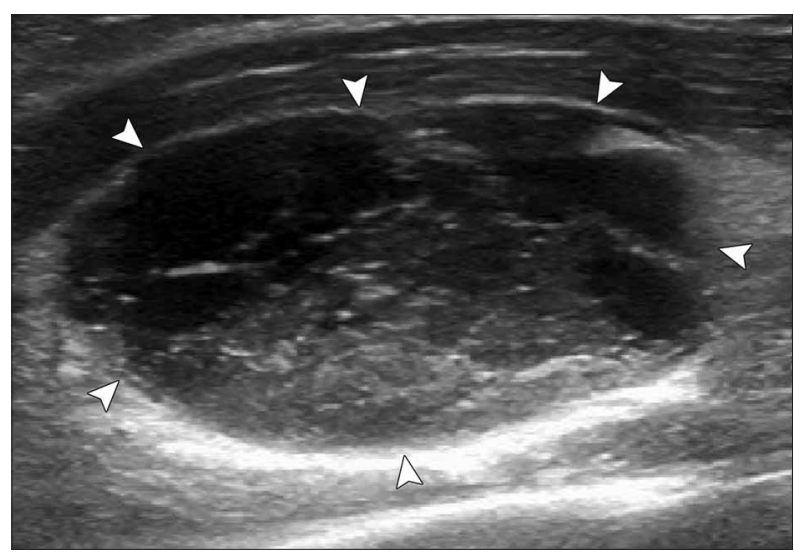

B

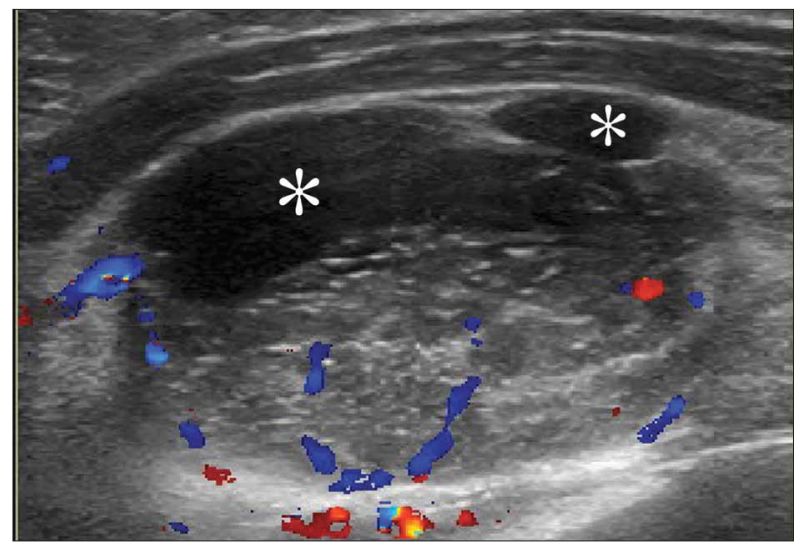




\section{References}

1. Smith SE, Salanitri J, Lisle D. Ultrasound evaluation of soft tissue masses and fluid collections. Semin Musculoskelet Radiol 2007; 11:174-191.

2. Springfield DS, Sweet S. Tumors of the elbow. In: Baker CL Jr (ed). Operative Treatment of Elbow Injuries. New York, NY: Springer; 2002:295302.

3. Myhre-Jensen O.A consecutive 7-year series of 1331 benign soft tissue tumors: clinicopathologic data — comparison with sarcomas. Acta Orthop Scand 1981; 52:287-293.

4. Fornage BD, Tassin GB. Sonographic appearances of superficial soft tissue lipomas. J Clin Ultrasound 1991; 19:215-220.

5. Mintz AD, Mengoni P. Angiolipoma of the breast: sonographic appearances of two cases. JUltrasound Med 1998; 17:67-69.

6. Wang Y, TangJ, Luo Y. Sonographic diagnosis of fibromatosis.J Clin Uttrasound 2008; 36:330-334.

7. Akisue T, Matsumoto K, Kizaki T, et al. Solitary fibrous tumor in the extremity: case report and review of the literature. Clin Orthop Relat Res 2003; 411:236-244.

8. DrapéJL, Feydy A, Guerini H, et al. Vascular lesions of the hand. EurJRadiol 2005; 56:331-343.

9. Rossi G, Iannicelli E, Almberger M, Innocenzi D, David V. Cystic lymphangioma of the upper extremity: US and MRI correlation (2004:1 1b). Eur Radiol 2005; 15:400-402.

10. Schwartz SA, Taljanovic MS, Harrigal CL, Graham AR, Smyth SH. Intravascular papillary endothelial hyperplasia: sonographic appearance with histopathologic correlation. J Ultrasound Med 2008; 27:1651-1653.

11. Lee HS, Joo KB, Song HY, et al. Relationship between sonographic and pathologic findings in epidermal inclusion cysts. J Clin Ultrasound 2001; 29:374-383

12. Vandevenne JE, Colpaert CG, De Schepper AM. Subcutaneous granuloma annulare: MR imaging and literature review. Eur Radiol 1998; 8:1363-1365.

13. Hwang JY,Lee SW, Lee SM. The common ultrasonographic features of pilomatricoma. J Ultrasound Med 2005; 24:1397-1402.

14. Reynolds DL Jr, Jacobson JA, Inampudi P, Jamadar DA, Ebrahim FS, Hayes CW. Sonographic characteristics of peripheral nerve sheath tumors. AJR Am J Roentgenol 2004; 182:741-744.

15. Girish G, Jamadar DA, Landry D, Finlay K, Jacobson JA, Friedman L. Sonography of intramuscular myxomas: the bright rim and bright cap signs. JUltrasound Med 2006; 25:865-869. 